\title{
Escritura académica con Tecnologías de la Información y la Comunicación en Educación Superior
}

\section{Academic writing with information and communications technology in Higher Education}

\author{
María Teresa Valverde González \\ Universidad de Murcia, Murcia, España \\ mariateresa.valverde@um.es
}

\begin{abstract}
Resumen
Este artículo presenta una revisión crítica de la literatura sobre las relaciones entre la educación lingüístico-literaria y la tecnología. El objetivo de la revisión es elucidar las experiencias de investigación relevantes sobre este tema, basándose en la hipótesis demostrada en las conclusiones de que la escritura académica, debido a su complejidad actual, debe ser trabajada necesariamente con el sustento estratégico de las nuevas tecnologías de la Sociedad del Conocimiento. Como prueba se emplea una metodología de Análisis Crítico del Discurso (ACD) para la indagación de diversas investigaciones científicas centradas en el estudio de distintas herramientas de producción digital de textos académicos útiles para el acceso y la comunicación sobre el saber científico. En suma, este análisis teórico aporta al profesorado y al alumnado universitario conocimiento actualizado de aquellos soportes digitales que han demostrado su eficacia desde un punto de vista epistémico y didáctico para contribuir al desarrollo de la competencia en escritura académica en Educación Superior.
\end{abstract}

Palabras clave: escritura académica, Educación Superior, Tecnologías de la Información y la Comunicación (TIC).

\begin{abstract}
This article presents a critical review of the literature on the relationship between linguisticliterary education and technology. The aim of the foresaid review is to elucidate the relevant research experiences on this subject, based on the demonstrated hypothesis in the conclusions that academic writing, due to its current complexity, must necessarily be worked with the strategic sustenance of the new technologies of the Knowledge Society. As proof, a methodology of Critical Discourse Analysis (CDA) is used for the investigation of diverse scientific researches focused on the study of different digital production tools of academic texts which are useful for the access to and communication about scientific knowledge. To sum up, this theoretical analysis provides lecturers and university students with up-to-date knowledge of those digital media that have been proven to be effective from an epistemic and didactic point of view to contribute to the development of the academic writing competence in Higher Education.
\end{abstract}

Keywords: academic writing, higher education, information and communications technology (ICT).

\section{Introducción}

Este trabajo presenta una revisión crítica de la literatura sobre las relaciones entre la enseñanza y el aprendizaje de la educación lingüístico-literaria y los medios tecnológicos. El objetivo de la revisión efectuada ha sido esclarecer qué contribuciones investigadoras se han producido en torno a la temática y cómo pueden beneficiar para el desarrollo de la escritura académica. La indagación se realiza mediante la metodología de Análisis Crítico del Discurso (ACD) (Fairclough, 2003; Wodak y Meyer, 2003), 
cuyos análisis se fundamentan en la Semiótica (Peirce, 2005; Saussure, 1945) y, en particular, en la indagación de discursos en sociedades. En concreto, el estudio se centra en el análisis de distintas perspectivas investigadoras con el propósito de comparar estos textos digitales críticamente en su interdiscursividad para alcanzar una función social: contribuir la adquisición de la escritura académica. Consecuentemente, se analizan diversos estudios empíricos acerca de la mejora de la competencia en escritura académica a través de las Tecnologías de la Información y la Comunicación (TIC) atendiendo tanto a aquello que atañe a la producción digital de textos académicos como al acceso al conocimiento científico. Este análisis teórico aporta a profesorado y alumnado conocimiento actualizado acerca de aquellos recursos tecnológicos que han demostrado su validez desde un punto de vista epistémico y didáctico para contribuir al desarrollo de la competencia en escritura académica propia de la Educación Superior.

La escritura académica es el principal vehículo de transmisión y difusión del conocimiento empleado por los investigadores. Consecuentemente, este tipo de escritura de alto nivel cognitivo constituye un sustento básico del proceso de capacitación del estudiante universitario, pues la Educación Superior es la principal responsable de formar a los futuros profesionales en la competencia expresiva necesaria para comunicarse con otros expertos y difundir sus hallazgos científicos (Carlino, 2003; Cassany y Morales, 2008; et al.). No obstante, a pesar de los esfuerzos emprendidos por las instituciones universitarias y su profesorado, los discentes no siempre superan sus estudios superiores con una adquisición adecuada de la competencia en escritura académica resuelta a través de estrategias lectoescritoras eficaces en la construcción creativa y crítica de conocimiento.

La literatura científica generada en torno a este tema alerta sobre diversas problemáticas frecuentes entre este colectivo, a saber: escaso acercamiento a las lecturas académicas y falta de capacidad crítica (Carlino, 2003; Cassany y Morales, 2008; Clerici, Monteverde y Fernández, 2015; et al.); dificultades en la comprensión de textos académicos manifestadas en la incapacidad para descubrir el objetivo principal de un texto, discernir entre las ideas principales y secundarias o la falta de dominio del vocabulario especializado de la disciplina imprescindible para una comprensión precisa (Alcover, Pabago, Lombardo, Gareca y Curone, 2015; Arrieta, Bautista, Meza y Meza, 2006; Delgadova y Gullerova, 2015; et al.); el uso ineficiente de las normas ortográficas y gramaticales adquiridas en su formación lingüística al producir faltas en el uso de los signos de puntuación y auxiliares, errores de concordancia, empleo de solecismos, dequeísmos, entre otros (Fajardo, 2013; Gómez y Gómez, 2015; Melguizo, 2016; et al.); dificultades para elaborar textos coherentes, cohesionados y con adecuación al crear escritos sin una estructura lógica definida, que no mantienen el hilo argumental, con escasos conectores de cohesión textual o con un registro discursivo inadecuado (Gallego-Ortega, García-Guzmán y Rodríguez-Fuentes, 2013; Serafini, 1994; et al.); desconocimiento de los formalismos vinculados a los géneros textuales de corte academicista al no respetar las particularidades normativas vinculadas al género en la producción (Bono y de la Barrera, 1998; Camps, 2007; Jarpa, 2013; et al.); el manejo inapropiado de los textos ajenos al emplearlos sin la mención conveniente y vulnerando los derechos de autor o el uso de fuentes de información sin prestigio reconocido (Egaña, 2012; Cayuela, Tauste, Seguí, Esteve y Ronda, 2015; Gallent y Tello, 2017; et al). En suma, queda patente que el alumnado universitario presenta carencias vinculadas

Escritura académica con Tecnologías de la Información y la Comunicación en Educación Superior. María Teresa Valverde González. 
a la lectura y la producción de textos académicos que han repercutido negativamente en el desarrollo de su competencia en escritura académica.

Este panorama de estudios interesados en la investigación sobre la formación en escritura académica de los estudiantes universitarios también se debe a la importancia que dicha competencia detenta en su aprendizaje a lo largo de la vida y, en especial, a su opción profesionalizadora, por tratarse de generaciones venideras de investigadores e investigadoras responsables de desarrollarse profesionalmente accediendo al conocimiento científico y de difundir los progresos alcanzados en su disciplina a otros expertos del área. Tales acciones son imprescindibles para el avance científico de las disciplinas y, sin un dominio eficaz de la escritura en maestría académica, resulta una labor de difícil consecución.

Por ello, han surgido diversas indagaciones científicas orientadas a contribuir en la mejora de este horizonte. Destacan aquellas que, conectando con la perspectiva tecnológica preponderante, exploran la valía pedagógica que los soportes digitales ostentan para la corrección o el perfeccionamiento de la competencia en escritura académica (Álvarez y Blassa, 2013; Álvarez, Mateo, Serrano y González, 2015; Figueroa y Aillon, 2015; Figueroa, Aillon y Fuentealba, 2014; Llanos y Villayandre, 2014; Martí y Martínez, 2014; et al.). Este enfoque se justifica en las diferentes regulaciones emanadas desde la Unión Europea que instan a la incorporación de Tecnologías de la Información y la Comunicación (TIC) en la práctica educativa debido a que albergan un alto potencial didáctico y a que su dominio eficiente resulta fundamental para la correcta integración profesional y social de los discentes (Comisión Europea, 2004; Consejo de Europa, 2001; Eurydice, 2012; OCDE, 2005a, 2005b; et al.).

Además, la tendencia institucional y científica actual también atiende a una realidad que afecta al colectivo universitario: este a menudo presenta carencias vinculadas al uso de las tecnologías ya que, si bien demuestra dominio lúdico de tales medios, no obstante, falla al aplicarlas en un contexto formal, especialmente en la transposición de los conocimientos académico-científicos adquiridos en sus estudios universitarios (Bennett, Maton y Kervin, 2008; Eurydice, 2011; Gutiérrez y Tyner, 2012; Unesco, 2011; Wilson, 2012; et al.). En definitiva, desde esta perspectiva se pretende contribuir no solo a enriquecer la escritura académica del alumnado con la ayuda de los medios tecnológicos, sino también a que estos desarrollen destrezas vinculadas a su competencia digital que son imprescindibles para su futuro académico y profesional.

\section{Estudio del arte de la cuestión y revisión de la literatura científica}

\section{Recursos digitales para el acceso al conocimiento científico y académico}

La aproximación lectora del alumnado universitario hacia la literatura científicoacadémica afín a su disciplina resulta una acción imprescindible si se pretende que estos elaboren textos fehacientes y que respondan adecuadamente a las tendencias epistemológicas emanadas del área de estudio en la que se ubican. La lectura de textos académicos proporciona a los estudiantes modelos de escritura válidos que enriquecen sus nociones en escritura académica y ejemplos concretos de multimodalidad escritora

Escritura académica con Tecnologías de la Información y la Comunicación en Educación Superior. María Teresa Valverde González.

Página 3 de 21 
que les sirvan como modelos textuales de redacción experta en investigación científica. El contar con referentes de escritura rigurosos y acordes a la disciplina de estudio es una acción fundamental previa para la correcta adquisición de la escritura académica, así como para el perfeccionamiento profesional vinculado a la disciplina estudiada.

No obstante, una de las principales problemáticas del alumnado universitario es que, con asiduidad, tiende a utilizar fuentes de información de procedencia poco recomendable que desacreditan su discurso. De hecho, lo convencional es que en la búsqueda documental efectuada para sus trabajos utilicen con mayor frecuencia los buscadores genéricos que los buscadores especializados y las bases de datos (Casanovas y Campos, 2014). Todo ello ha promovido la producción de infinidad de trabajos inspirados en fuentes de dudosa reputación que ha repercutido negativamente en la producción científico-académica estudiantil. En efecto, esta circunstancia ha suscitado preocupación en los ámbitos educativo e investigador pues no importa el género académico desde el que se ubique un texto, en la producción académica o científica no se puede renunciar a la utilización de fuentes de información fiables que den crédito a las palabras y enriquezcan epistemológicamente a aquel que lee.

En consecuencia, los investigadores han dirigido sus estudios hacia la recopilación, análisis, aplicación y evaluación de un amplio repertorio de entornos digitales útiles para la consulta científica, enciclopédica o de información de actualidad que resultan imprescindibles en la formación de los estudiantes universitarios al proveerles de conocimiento académico y científico de interés para su formación. Se entiende que el aprendizaje del empleo eficaz de estos espacios previene ante el uso de fuentes de información irrelevantes e inicia en los modos de búsqueda y selección de información propios de expertos. Los emplazamientos digitales que más han demostrado su eficacia en la práctica docente vinculada a la lectura académica son los siguientes (Gutiérrez 2009; Izquierdo, Renés y Gómez, 2013; Llanos y Villayandre, 2014; et al.):

- Las bases de datos se constituyen como uno de los espacios más significativos al proveer al alumnado de publicaciones científicas y académicas de diversa naturaleza. La importancia de que se familiaricen con ellas y las incorporen a su práctica habitual reside no solo en la cantidad de producciones que se puede localizar, sino también en la calidad de los contenidos albergados, ya que estas han superado un riguroso proceso de evaluación por expertos que garantiza su riqueza epistemológica y didáctica. Esta acción permitirá sustentar sus saberes en conocimientos fidedignos y relevantes para el área de estudio. En el ámbito vinculado a la educación destacan espacios como Dialnet, base de datos del CSIC, Redalyc, Redib, Redined, Tesis Doctorales en Red, Scielo, Eric o Web of Science.

- Las bibliotecas virtuales son otra fuente de recursos bibliográficos valiosos para los discentes al proveer de contenido libre o indicar la ubicación física de la obra elegida para su consulta presencial o la solicitud de un préstamo bibliotecario. La Biblioteca Nacional de España, la Biblioteca Virtual del CSIC, la Biblioteca Virtual Miguel de Cervantes, la amplia red de bibliotecas regionales ubicadas en la Web o las propias bibliotecas ofrecidas por la universidad de origen se conforman como un extenso repertorio lector de interés para los discentes que contribuye a su formación disciplinar y garantiza su acceso a conocimientos de calidad.

- Las revistas digitales de acceso libre también pueden resultar provechosas para la formación del alumnado al difundir de forma periódica artículos de interés para su

Escritura académica con Tecnologías de la Información y la Comunicación en Educación Superior. María Teresa Valverde González. 
área de estudio o con carácter multidisciplinar. Estas publicaciones superan un exigente proceso de elección por parte de evaluadores especializados en la materia, lo cual da garantías de que la información recibida tenga gran valor para la disciplina. Además, su importancia también reside en que este tipo de publicación son uno de los principales medios de comunicación científica y, por tanto, uno de los ejemplos más representativos para el alumnado sobre la manera en que se transmite el conocimiento en su disciplina, lo cual les permite conocer e incorporar progresivamente a su repertorio expresivo las tendencias discursivas del ámbito de estudio, trabajo imprescindible en su formación como futuros profesionales del área. En el ámbito educativo destacan las revistas Comunicar, Revista Española de Pedagogía, Revista de Educación, Revista Educación XX1, RED -Revista de Educación a Distancia, Revista de Investigación Educativa, Cuadernos de Pedagogía, entre otras.

- Los periódicos digitales destacan por proveer información de actualidad diariamente, lo cual posibilita a los discentes estar al tanto de los asuntos de impacto más recientes que preocupan a la sociedad y afectan al área de estudio. El País, El Mundo, La Vanguardia, ABC, etc., la mayor parte de los periódicos de tirada nacional o regional ofrecen una versión electrónica libre que puede consultarse en la Web a diario.

- Los diccionarios en línea ofrecen un repertorio electrónico de términos acompañados de su definición que pueden aclarar al alumno durante la lectura si este desconoce alguna palabra. La Real Academia Española cuenta una versión en línea del Diccionario de la lengua española (2017), el Diccionario panhispánico de dudas (2005).

La introducción de estos espacios digitales en el aula no se limita a la mera presentación de aquellas ubicaciones que son enriquecedoras para el acceso al conocimiento científico y a la enseñanza de su manejo eficaz, sino que es recomendable involucrar al alumnado en tareas que impliquen explorar dichos espacios y leer literatura disciplinar para su comprensión crítica, pues solamente mediante la práctica se desarrollarán las destrezas necesarias para su dominio eficaz. Esto puede lograrse mediante la realización de trabajos tales como de artículos de investigación, artículos de revisión, proyectos de investigación, ensayos, etc., y, en definitiva, cualquier trabajo de corte academicista donde el alumnado tenga que localizar conocimientos científico-académicos, analizarlos, comprenderlos y expresarlos por escrito.

Otra forma de iniciar al alumnado en las lecturas académicas, que también puede complementar a la anterior sugerencia, es involucrarlo en la realización de dinámicas en grupo donde se analice, discuta y reflexione sobre textos académicos de forma colectiva para aprender estrategias comprensivas que resulten eficaces y se intercambien conocimientos acerca del tema.

Por otra parte, debido a la complejidad de los saberes emanados de las distintas disciplinas científicas, siempre que se considere oportuno, el profesorado deberá considerar el hecho de ofrecer glosarios con terminología afín a la disciplina que permitan al alumnado familiarizarse con el discurso académico y le faciliten la comprensión de los textos académicos.

Escritura académica con Tecnologías de la Información y la Comunicación en Educación Superior. María Teresa Valverde González. 


\section{Recursos digitales para el desarrollo de la competencia en escritura académica}

La mera lectura de textos académicos no es suficiente para la mejora de la competencia en escritura académica, esta debe complementarse con acciones didácticas donde sean los propios estudiantes los encargados de producir textos científico-académicos (artículos de investigación, artículos de revisión, comunicaciones para congresos, ensayos, proyectos de investigación, etc.). En efecto, no se puede desarrollar la competencia en escritura académica sin experimentar con autonomía la producción de textos académicos dado que esta experiencia permite al alumnado adquirir el soporte conceptual y procedimental imprescindible para ser un escritor eficaz.

En las prácticas de escritura académica realizadas en el ámbito universitario han surgido diferentes recursos tecnológicos vinculados a la producción digital de interés para los discentes. Entre ellos es reseñable especialmente el procesador de textos (Figueroa, Aillon y Fuentealba, 2014; Figueroa Aillon y Salazar, 2013; Solano, 2013; et al.), el cual se ha convertido en uno de los programas más utilizados para la escritura académica debido a sus cualidades para la edición y maquetación de textos. Este recurso facilita al discente la labor de adaptar el formato del texto al tipo de género escogido, cumplir con las normas de presentación (sangría, interlineado, párrafo, etc.); mejorar la cohesión textual al emplear el diccionario de sinónimos o consultar definiciones de palabras de las cuales no se tiene del todo claro el significado; revisar ciertos elementos ortográficos y gramaticales del texto gracias al corrector automático; obtener una ayuda con la creación de las referencias; contar el número de palabras para no superar el máximo estipulado por el docente (si es el caso); incluir tablas, imágenes o figuras de diseño propio que complementen el discurso y aclaren al lector; realizar índices de contenidos en trabajos extensos. Estas opciones tan diversas han propiciado que el procesador sea el programa más demandado para la práctica discente debido a su gran su utilidad.

Pero no solo facilita la escritura digital a los estudiantes, el profesorado también puede beneficiarse de sus potencialidades en sus diseños didácticos. El procesador de textos le ofrece la posibilidad de dar asesoramiento mientras que sus alumnos escriben, ya que este puede anotar comentarios con la opción correspondiente dentro del propio texto en distintas etapas de la elaboración (Llanos y Villayandre, 2014; Morales y Espinoza, 2005; et al.). Por otra parte, también admite diseñar plantillas digitales con instrucciones procesuales para la redacción que doten de autonomía al discente durante la escritura (Figueroa y Aillon, 2015; Figueroa, Aillon y Fuentealba, 2014; et al.). Además, en sus versiones en línea, como pueden ser Google Drive o Microsoft Office Online, se pueden crear experiencias de escritura colaborativa donde construir el conocimiento de forma conjunta (Álvarez y Bassa, 2013; Izquierdo, Renés y Gómez, 2013; Monzón, 2011; et al.) o individualizada. Estas aplicaciones destacan no solo porque dejan ver la evolución del escrito del alumnado durante su concepción, sino también donde poder contar con registro procesual con las diferentes modificaciones realizadas en el texto y una contabilización del tiempo invertido en el trabajo. Asimismo, estas plataformas posibilitan la realización de comentarios en el propio texto que son recibidos de forma instantánea al correo electrónico de los estudiantes, lo cual promueve una comunicación activa entre el docente y alumnos y facilita el control procesual. Igualmente, tanto el procesador de texto convencional como el en línea, son herramientas útiles diseñar rúbricas que fomenten la autoevaluación, coevaluación o heteroevaluación (Cáceres-

Escritura académica con Tecnologías de la Información y la Comunicación en Educación Superior. María Teresa Valverde González. 
Lorenzo y Santana-Alvarado, 2014; Saneleuterio, 2015; Muñoz y Valenzuela, 2015; et al.).

Otro de los recursos demandados para la escritura académica ha sido el blog. Diversos emplazamientos digitales tales como Blogger, Blogspot o WordPress ofrecen al usuario la posibilidad de crear de forma gratuita un espacio digital propio donde realizar publicaciones periódicas que incluyan texto, enlaces, imágenes, vídeos o archivos de audio. Esta herramienta ha demostrado ser útil para la producción y difusión de contenidos académicos con lenguaje multimedia. Se admite la creación de un blog de aula donde los propios alumnos publiquen artículos de investigación, artículos de revisión, ensayos, reseñas, vídeo-reseñas, etc., de interés para la disciplina; reflexionen sobre escritura académica a partir de la lectura y análisis de los trabajos realizados; accedan a información de interés para el perfeccionamiento de su escritura académica; descarguen plantillas de escritura; visualicen eventos académicos como congresos para comentarlos y reflexionar sobre ellos; reciban asesoramiento virtual del docente.

Por otra parte, el blog también permite la realización de acciones colaborativas gracias a sus potencialidades para la escritura en grupo y la creación de redes de aprendizaje mediante las que construir colectivamente el conocimiento (Álvarez y Bassa, 2013; Figueroa y Aillon, 2015; et al.). Ello podría dirigir, por ejemplo, hacía la creación de un periódico o revista escolar gestionado íntegramente por el alumnado — bajo la supervisión del profesor - en el que escribir sobre temas de actualidad, reflexionar acerca de asuntos académicos, dar difusión a las propias creaciones científicas, entre otros. Una de las principales ventajas de esta incursión digital para el alumnado es que ofrece la posibilidad de hacer público el trabajo realizado y que este sea visible más allá del profesor, creando así motivación para realizar la tarea y satisfacción por su conclusión y presentación al público (Martín y Martínez, 2014). Por otra parte, en lo que afecta al docente, esta le permite contar con un historial de todas las publicaciones y sus correspondientes ediciones, registros de gran interés para la realización de un seguimiento procesual de la escritura de los estudiantes.

Además de las herramientas comentadas para la producción digital se incorporan otras de carácter complementario y de interés para el perfeccionamiento de la escritura académica, como lo son aquellas útiles para la adquisición de conocimientos conceptuales que refuercen los saberes existentes, el asesoramiento procesual mientras se escribe y la interacción digital entre tutores expertos y alumnado. Sirvan de ejemplo ilustrativo las siguientes iniciativas universitarias:

- La plataforma interactiva RedacText 2.0 (http://www.redactext.es/index.php/introduccionmenuplataforma) ha sido creada por el grupo de investigación Didactext (Didáctica de la escritura) de la Universidad Complutense de Madrid (2001), coordinado por Teodoro Álvarez Angulo, y está especializada en el estudio de los procesos de enseñanza-aprendizaje de los textos académicos. Este entorno digital interactivo ofrece la secuencia procesual de la escritura centrándose en las etapas escritoras de planificación, producción, revisión y rescritura, edición y presentación. El usuario encuentra distintas actividades y herramientas de apoyo que le dirijan a la adquisición de habilidades propias de un escritor experto. Además, se ofrecen instrucciones tanto al profesorado como al alumnado participante.

Escritura académica con Tecnologías de la Información y la Comunicación en Educación Superior. María Teresa Valverde González. 
- LEA lab (http://www.miaprendizaje.uchile.cl/laboratoriolea/) es una plataforma procedente de la Universidad de Chile que facilita diferentes cursos virtuales sobre escritura académica consistentes en la resolución de diferentes ejercicios con retroalimentación instantánea y estrategias de autoevaluación individualizadas para que los estudiantes mejoren su escritura con autonomía. Los cursos se caracterizan por incluir no solo información precisa sobre los conocimientos tratados en el curso, sino también cuentan con diferentes ejemplos textuales realizados por el propio alumnado universitario.

- El Centro de escritura javeriano de la Pontificia Universidad Javeriana de Cali (Colombia) (http://centrodeescritura.javerianacali.edu.co/) da acceso a recursos para profesores y alumnos de escritura académica desde una perspectiva procesual, además de contar con servicios de tutoría gratuita.

- La Escuela de escritura de la Universidad de Alcalá (https://portal.uah.es/portal/page/portal/escuela_escritura) ofrece un servicio para la resolución de dudas linguísticas en línea, así como para la corrección de textos de textos académicos.

- El Centro virtual de escritura de la Universidad de Buenos Aires (https://centrodeescrituravirtual.wordpress.com/) facilita recursos sobre escritura académica con una secuencia procesual y un servicio de consulta en línea.

Por tanto, las plataformas virtuales diseñadas para la escritura académica no se han limitado a ser meros repositorios de conocimientos, sino que también adquieren una función interactiva al propiciar el asesoramiento virtual sobre dudas lingüísticas, la corrección de trabajos en línea o la realización de ejercicios para recibir una retroalimentación inmediata.

Otro aspecto fundamental es que todos los recursos facilitados para la construcción de los distintos géneros textuales se proveen atendiendo a fases escritoras de ideación, textualización y revisión emanadas de la actual corriente procesual de la escritura procedente de la Didáctica de la Lengua y la Literatura, la cual demuestra la importancia de incidir sobre estos procesos de escritura si se aspira a ofrecer una enseñanza adaptada a las necesidades de aprendizaje de los estudiantes (Bereiter y Scardamalia, 1992; Flower y Hayes, 1981; Hayes, 1996; et al.). Asimismo, se caracterizan por proveer de ejemplos concretos de escritura de investigadores expertos y de alumnado con el mismo nivel madurativo que los implicados en coherencia con los hallazgos científicos acerca de su importancia para orientar la modelización escrita (Drop, 1987).

En suma, estas incursiones ofrecen no solo recursos útiles para que los discentes adquieran saberes con autonomía, sino también para que el docente obtenga pistas acerca de qué diseños didácticos resultan más enriquecedores para construir entornos virtuales personalizados con ayuda del soporte tecnológico ofrecido por su propia universidad, como puede ser el aula virtual, o mediante el diseño de una página web, un blog o una wiki personal.

Por otra parte, desde el ámbito lingüístico surgen espacios de provecho para el conocimiento enciclopédico de la lengua española, saberes imprescindibles para el perfeccionamiento de la escritura académica y que deben formar parte del proceso formativo de los discentes. Destaca la web de la Real Academia Española, la cual da

Escritura académica con Tecnologías de la Información y la Comunicación en Educación Superior. María Teresa Valverde González. 
acceso de forma gratuita a las versiones digitales del Diccionario de la lengua española (2017) o el Diccionario panhispánico de dudas (2005), útiles para la consulta del significado de distintos términos o la resolución de dudas lingüísticas frecuentes (http://www.rae.es/recursos/diccionarios); así como al Ortografía de la lengua española (2010), en su versión beta, la cual permite solucionar dudas sobre la nueva ortografía española.

Por otro lado, también es de interés Fundéu BBVA, un buscador de dudas en español asesorado por la Real Academia Española que posibilita la localización de preguntas lingüísticas en la propia web a partir de la visualización de otras consultas realizadas, o bien de mediante el envío de la cuestión que se desea esclarecer para que esta sea respondida (http://www.fundeu.es/). Igualmente, resulta de reseñable Wikilengua, espacio patrocinado por Fundéu BBVA y la Agencia EFE que compila diferentes saberes asociados la norma, el uso y el estilo lingüístico (http://www.wikilengua.org/index.php/Portada). Además, importa destacar el diccionario WordReference, útil para consultar sinónimos y anónimos (http://www.wordreference.com/sinonimos/).

A lo ya mencionado se han de añadir aquellas herramientas digitales que resultan útiles para la organización y gestión de la bibliografía, ya que en la escritura académica se suele trabajar con amplios listados de referencias de autores y su fácil organización puede facilitar la tarea a aquel que escribe. Es destacable el programa Zotero por su sencillez, un gestor de referencias bibliográficas gratuito que permite guardar, gestionar y citar las diferentes publicaciones recolectadas de Internet. Este se instala como extensión en Google Chrome o Firefox y permite al usuario almacenar y organizar su bibliografía desde el propio explorador. Además, admite la instalación de un complemento que lo integra en Microsoft Word y posibilita el citado automático (https://www.zotero.org/). A este se incorpora Mendeley, el cual posee funciones similares a las comentadas, pero también incluye una aplicación para gestionar el programa desde el propio escritorio y la posibilidad de compartir las referencias con otros usuarios (https://www.mendeley.com/). Igualmente válidos son RefWorks (https://www.refworks.com/es/), EndNote (http://endnote.com/) o JabRef (http://www.jabref.org/). El usuario puede seleccionar el entorno que se adapte mejor a sus necesidades.

En la misma línea, para el referenciado de archivos de Internet con URL puede resultar práctica la aplicación web Bitly — una de las sustitutas de Google URL Shortener, el cual recientemente anunció su cierre definitivo-, la cual acorta direcciones muy extensas para que a la hora de incluirlas en las referencias estas no ocupen demasiado espacio. Esta herramienta es especialmente útil cuando se tienen muchas referencias con direcciones muy largas y existe una limitación de páginas el trabajo demandado (https://bitly.com/).

Del mismo modo, puesto que ya con anterioridad se manifestó que el plagio académico es un tema que suscita preocupación (Egaña, 2012; Cayuela, Tauste, Seguí, Esteve y Ronda, 2015; Gallent y Tello, 2017; et al), se han de mencionar también aquellos recursos electrónicos diseñados para detectarlo. Estos interesan tanto al profesorado como al propio alumnado, ya que este último puede usarlos cuando tiene dudas acerca de si ha realizado convenientemente el citado y referenciado bibliográfico y el docente cuando tiene sospechas de posible plagio.

Escritura académica con Tecnologías de la Información y la Comunicación en Educación Superior. María Teresa Valverde González. 
El funcionamiento de estos programas consiste en la inserción de un texto o un documento del que se tiene desconfianza sobre su autoría para que este posteriormente busque coincidencias en el contenido publicado en Internet. Finalmente, el usuario recibe (si hay plagio) un listado de sitios o archivos donde existen coincidencias. Generalmente, se señalan en el documento plagiado aquellas secciones que son idénticas y un porcentaje total del plagio cometido. Existen programas que deben instalarse en el ordenador para su utilización y que no siempre son gratuitos en sus versiones completas como Turnitin (http://turnitin.com/es/) o Viper (https://www.scanmyessay.com/), pero también otros que no requieren instalaciones y pueden gestionarse en línea como DupliCheker (https://www.duplichecker.com/), Plagiarism Checker (https://edubirdie.com/plagiarism-checker), Plagiarisma (http://plagiarisma.net/es/) o Plagium (http://www.plagium.com/es/detectordeplagio). La principal desventaja de estos últimos es que suelen tener restricciones en el número de palabras o en el número de búsquedas diarias en sus versiones gratuitas.

\section{Tendencias pedagógicas en la didáctica de la escritura académica con soportes digitales}

La revisión crítica de la literatura sobre las relaciones entre el desarrollo de la escritura académica y la tecnología efectuada permite extraer tendencias didácticas generales en el diseño y aplicación de acciones en el aula universitaria que se pueden simplificar en la siguiente secuencia procesual (Álvarez, 2012; Casanovas y Campos, 2014; Figueroa y Aillon, 2015; García y Martí, 2017; Llanos y Villayandre, 2014; Martín, 2011; Martín y Martínez, 2014; Morales y Espinoza, 2005; Padilla, 2012; et al.):

1) Detección de los conocimientos previos en escritura académica mediante la realización de un cuestionario que explore sus saberes y la elaboración de un género académico donde se refleje su capacidad para aplicarlos.

2) Corrección y esclarecimiento de los resultados obtenidos en la evaluación inicial mediante la tutoría individualizada o la tutoría colectiva, informando de deficiencias y potencialidades y solicitando demandas en escritura académica.

3) Ofrecimiento de los complementos formativos requeridos por el alumnado a partir de sus necesidades y demandas en escritura académica mediante la clase magistral o virtual. Se centra la atención en conocimientos clave para la escritura de corte academicista, a saber: características generales de la escritura académica; particularidades del género textual que se va a desarrollar y explicación de la secuencia procesual atendiendo a las clásicas fases de ideación, textualización (coherencia, cohesión y adecuación) y revisión; actualización de las novedades lingüísticas surgidas; ofrecimiento de un sistema de citado y referenciado conveniente para la disciplina de estudio.

4) Presentación y recomendaciones de uso de aquellos espacios digitales que pueden ser de utilidad para la lectura y escritura académica que se emplearán a lo largo de la aplicación (bases de datos, bibliotecas virtuales, diccionarios, etc.).

5) Entrega de materiales didácticos procesuales (impresos o virtuales) que asesoren durante la lectura y la producción escrita y complementen los conocimientos recibidos con anterioridad.

Escritura académica con Tecnologías de la Información y la Comunicación en Educación Superior. María Teresa Valverde González. 
6) Diseño de tareas orientadas a la lectura y análisis crítico de textos académicos, individualizadas y grupales, donde poder reflexionar acerca de los conocimientos adquiridos de la disciplina y sobre la escritura académica.

7) Aplicación de lo aprendido mediante la confección de un género textual propio de la escritura académica empleando un soporte digital (procesador de texto, blog, wiki, etc.) y con el apoyo procesual de los complementos didácticos.

8) Revisión procesual del trabajo académico realizado mediante la heteroevaluación (valoración de las producciones, aplicación de rúbricas, revisión de las diferentes versiones del documento o los historiales, anotaciones en diarios de campo, realización de entrevistas), la coevaluación y la autoevaluación (con el apoyo de las rúbricas ofrecidas por el profesor).

9) Lectura y análisis crítico de los trabajos realizados tanto por su valor epistemológico como por su coherencia en cuanto a la calidad de la escritura empleada.

10) Difusión de los trabajos en un espacio digital (blog, página web, wiki, etc.) o mediante la exposición pública de los mismos en un seminario o congreso.

\section{Conclusiones}

La escritura académica siempre ha adquirido un papel relevante en las enseñanzas universitarias por constituir una competencia prioritaria y transversal en el acceso al conocimiento científico y en la adquisición y la transferencia de saberes conceptuales y procedimentales.

Por su parte, cada disciplina académica se ha responsabilizado del ejercicio de esta competencia desde sus propias necesidades expresivas y repertorio referencial. De esta manera se cultiva la escritura académica en cada área de conocimiento con la aportación docente especializada en orientar a los estudiantes sobre aquellas particularidades que configuran su discurso y de prepararlos para su futura incorporación al mundo académico y profesional en dicha especialidad.

Esta especialización escritural multidisciplinar ha logrado mayor importancia con la implementación en los últimos años de los Trabajos Fin de Grado y los Trabajos Fin de Máster, los cuales han demandado del profesorado que acerque y asesore a sus alumnos hacia el procedimiento investigador propio de la disciplina en la que se ubican y la escritura académica específica del área, en atención a las directrices generales coordinadas en cada centro de estudios.

No obstante, esta compleja labor formativa ha dejado patente que los discentes no siempre dominan convenientemente la escritura en relación con las expectativas correspondientes a su edad madurativa ni son capaces de adoptar la comunicación científica de la disciplina de forma eficaz (Caro y Valverde, 2014; Corcelles, Cano, Bañales y Alicia, 2013; López-Cózar, Priede y Benito, 2013; et al.). Esta realidad ha dirigido hacia un acto reflexivo investigador y de experimentación pedagógica orientado a lograr descubrir aquellos recursos o medios que contribuyen para remediar las carencias existentes o ayudan en el perfeccionamiento de la escritura académica.

En este sentido, la indagación emprendida ha centrado su interés en las nuevas tecnologías existentes debido a que en la actualidad vivimos inmersos en lo digital y a

Escritura académica con Tecnologías de la Información y la Comunicación en Educación Superior. María Teresa Valverde González.

Página 11 de 21 
que estas se caracterizan por una multifuncionalidad que provee de diversos instrumentos que facilitan la acción escritora, la maquetación de textos, la realización de lecturas científicas, la obtención de conocimientos conceptuales y procedimentales sobre escritura académica, el acceso al saber enciclopédico referente a la lengua española, la resolución de dudas lingüísticas o la corrección de trabajos en línea, la gestión de la bibliografía, la detección del plagio y la comunicación entre profesorado y alumnado.

Los resultados de la realización de intervenciones didácticas contando con estos recursos demuestran que los estudiantes experimentan mejoras en sus producciones textuales, adquieren estrategias propias de un experto vinculadas a la lectura y la escritura académica, aprenden a confeccionar diferentes géneros académicos útiles para su futuro profesional, descubren nuevas formas de acercamiento al saber científico, desarrollan su pensamiento crítico, adquieren nociones para la difusión del conocimiento y, en definitiva, se les capacita para participar a la comunidad discursiva a la que pertenecen y a comunicarse de forma más eficiente con otros profesionales del área (Álvarez, Mateo y Serrano, 2015; Figueroa y Aillon, 2015; Figueroa, Aillon y Fuentealba, 2014; Llanos y Villayandre, 2014; Valverde, 2016; et al.).

En conclusión, este artículo afirma que hoy en día las labores de escritura académica resultan indisociables de las nuevas tecnologías y que la enseñanza de la escritura en la Educación Superior debe sustentarse de los aportes técnicos que estos recursos proveen. Tal afirmación se sustenta en cuatro razones educativas de interés comunicativo en la Sociedad del Conocimiento: en primer lugar, porque la escritura académica está inmersa en lo digital y no puede concebirse sin el uso de herramientas como el procesador de textos, las bases de datos, las bibliotecas virtuales o las páginas web especializadas; en segundo lugar, porque simplifica al alumnado una labor compleja y les permite acceder al conocimiento científico actual; en tercer lugar, porque facilita al profesorado la implementación de propuestas didácticas y les da la posibilidad de asesorar virtualmente a sus estudiantes y estar en contacto directo con ellos para orientarlos durante la creación de textos; en cuarto, porque son un medio de difusión científica que debe dominarse para el futuro profesional. Por tanto, es conveniente que toda acción didáctica emprendida para la adquisición de la escritura académica se nutra de los medios digitales para que la acción se enriquezca de las posibilidades técnicas que ofrecen y se corresponda a la perspectiva tecnológica preponderante.

\section{Discusión}

La perspectiva científica sobre la que se ha centrado esta revisión crítica de la literatura acerca de las relaciones entre el aprendizaje y la enseñanza de la escritura académica y las tecnologías se complementa con otro enfoque divergente, pero complementario, en el que se propicia la adquisición de la escritura académica sin el sustento del soporte informático.

Esta corriente antecede en sus orígenes al enfoque propuesto debido a que sus inicios son anteriores a la difusión de la actual revolución tecnológica. En ella se ubican diversas investigaciones cuyo principal propósito ha sido contribuir a la mejora de la competencia en escritura académica de los estudiantes para su desarrollo personal y profesional sin la intervención de los medios digitales. Estas incursiones se centran en la enseñanza de la lectura y escritura académica propia de discursos científicos localizando

Escritura académica con Tecnologías de la Información y la Comunicación en Educación Superior. María Teresa Valverde González. 
el acceso al conocimiento en bibliotecas y hemerotecas locales y difundiendo el saber a través de la escritura manuscrita o mecanografiada en diferentes géneros de corte academicista comunes en la difusión científica (Bono y Barrera, 1998; Bolibar y Montenegro, 2012; Molina, 2013; Cortés y García, 2013; Martín, 2011; et al.).

La secuencia didáctica propia de este primer enfoque es similar a la desplegada en la revisión pues se inicia con el acceso a la literatura científica concerniente al tema, prosigue con la lectura y reflexión y concluye con la escritura de un texto. Asimismo, se fundamenta en un proceso formativo, donde, a través de la clase magistral, la práctica y las tutorías personalizadas, se adquieran saberes sobre escritura académica y el género textual con el que se trabaja. Del mismo modo, se establece una secuencia basada en las en las fases clásicas de ideación (concepción del tema), textualización (coherencia, cohesión y adecuación textual) y revisión (escritura en borrador). Todo ello, con el asesoramiento procesual experto del profesorado, quien ofrece las retroalimentaciones adecuadas para el aprendizaje eficaz. Además, se facilitan recursos didácticos personalizados de interés sobre asuntos tales como las particularidades de la comunicación científica, el género textual tratado, los modos de búsqueda en bibliotecas o citado y referenciado. La calidad pedagógica del proceso efectuado se valora a través de distintos instrumentos de autoevaluación, coevaluación y heteroevaluación.

En esencia, desde esta corriente se mantiene la importancia de involucrar al alumnado en tareas donde aprenda a localizar el saber científico, realice lecturas comprensivas y críticas y escriba diferentes tipologías académicas. Todo ello, con el apoyo del asesoramiento del profesorado y los recursos didácticos generados. Este posicionamiento es semejante a las tendencias didácticas actuales emanadas en la enseñanza de las lenguas, sin embargo, aun brindando saberes y estrategias beneficiosas para la escritura académica, se considera que se brinda un tipo de enseñanza que no atiende al contexto comunicativo en el que se ve inmerso el alumnado, quien necesita desarrollar su competencia digital para su integración plena en la Sociedad del Conocimiento.

Esta perspectiva se establece atendiendo a las recomendaciones ofrecidas por la OCDE (2004) a la hora de definir las competencias clave que todo ciudadano europeo debe dominar para su incorporación democrática a la sociedad del siglo XXI, ya que reconoce como una acción imprescindible el ofrecimiento de aquellos conocimientos y destrezas necesarios para ser independiente en competencia digital. Esta capacitación se cataloga como transcendental para el crecimiento personal y profesional del individuo inmerso en una sociedad eminentemente tecnológica y digitalizada y, por ello, no se puede obviar en el ámbito educativo.

Una educación coherente con los niveles madurativos de los estudiantes universitarios les capacitará para acceder al conocimiento científico, comprenderlo críticamente, difundirlo con libertad e interaccionar con otros expertos, labor compleja sin el sustento tecnológico. Efectivamente, la capacidad de la Red para obtener saberes, difundir conocimientos o sus potencialidades para la interacción a escala mundial son elementos a los que un educador no puede declinar al vivir en una sociedad tecnológica.

Esta postura también es apoyada por el Consejo de Europa (2001), quien, a través del principal documento regulador de la enseñanza de las lenguas a nivel europeo, el Marco común europeo de referencia para las lenguas: aprendizaje, enseñanza, evaluación, señala la importancia de la adquisición de la competencia digital para la competencia

Escritura académica con Tecnologías de la Información y la Comunicación en Educación Superior. María Teresa Valverde González. 
comunicativa debido a que el lenguaje tecnológico se concibe como otra forma de expresión escrita que debe aprenderse para adquirir plenamente dicha competencia. Por tanto, una enseñanza sin tecnología debería catalogarse como inconclusa al no atender a las demandas contextuales requeridas al usuario de la lengua.

A lo anterior se le unen las recomendaciones emanadas de la red europea Eurydice (Consejo de Europa, 2011), quien alerta de que, aún existiendo una tendencia a considerar a los discentes como nativos digitales (Prensky, 2001), la realidad es que estos exhiben un dominio eficiente de la tecnología desde un punto de vista lúdico, pero ineficiente en el plano informal, lo que demanda de acciones específicas donde se enseñe a usar la tecnología para el aprendizaje de conocimientos académicos y destrezas eficientes para el tratamiento y análisis crítico de la información.

Del mismo modo, tal y como afirman otros investigadores relevantes para Didáctica de la Lengua y la Literatura como Cassany (2000), no se puede renunciar a las posibilidades técnicas que las tecnologías nos brindan para el aprendizaje de la lectura y la escritura al proveer de saberes ilimitados de acceso libre; en diferentes formatos gráficos, audiovisuales y multimedia; con carácter inmediato; con elementos interactivos, hipertextuales e intertextuales; y de bajo coste para el usuario.

En consecuencia, se estima que la comunidad internacional demanda de actuaciones educativas donde los estudiantes adquieran conocimientos y destrezas para la mejora de su competencia digital. Por ello, se considera que la revisión realizada logra mostrar a alumnado y profesorado una visión unificada de lo que dice el panorama científico y académico sobre cómo aprender o enseñar la competencia en escritura académica sirviéndose de aquellas opciones que les ofrece la tecnología, lo cual cubre los requerimientos internacionales y una laguna investigadora al no haber estudios que profundicen sobre este asunto.

Sin embargo, el análisis efectuado plantea la necesidad de profundizar sobre otras líneas investigadoras de interés para el avance epistemológico de las relaciones entre las TIC y la escritura académica. La primera línea sugerida sería indagar acerca del estudio de las capacidades específicas de los estudiantes en competencia digital para la mejora de su conocimientos y destrezas en escritura académica. Ello es debido al hecho de que, aunque existen estudios internacionales de gran envergadura concernientes al tema de sumo interés, la mayoría de ellos se centran en el uso general y cotidiano de las TIC y no profundizan sobre su empleo en contextos educativos formales. Se estima que el conocimiento de las necesidades de los estudiantes vinculadas a este ámbito resultan imprescindibles para formular demandas concretas que puedan ser cubiertas mediante una planificación didáctica adecuada.

La segunda línea investigadora consistiría en ahondar acerca de la combinación entre los recursos tecnológicos y la escritura académica en la enseñanza universitaria con un sector de la población representativo y generalizable, ya que las investigaciones existentes, aún ofreciendo resultados sumamente enriquecedores para el esclarecimiento epistémico de la cuestión, suelen contar con muestras reducidas que no pueden extrapolarse al resto de la población. Por tanto, se considera que la realización de estudios de mayor envergadura puede contribuir a ofrecer una visión más holística de la realidad que logre dar orientaciones enriquecedoras para un tratamiento más eficaz de las habilidades en escritura académica recibiendo el sustento de las nuevas tecnologías a profesorado y alumnado.

Escritura académica con Tecnologías de la Información y la Comunicación en Educación Superior. María Teresa Valverde González. 
Fecha de redacción: 24 de febrero de 2018

Presentación del artículo: 17 de marzo de 2018

Fecha de aprobación: 26 de octubre de 2018

Fecha de publicación: 31 de octubre de 2018

Valverde, M. T. (2018). Escritura académica con Tecnologías de la Información y la Comunicación en Educación Superior, RED: Revista de Educación a Distancia, 58. Consultado el (dd/mm/aaaa) en http://www.um.es/ead/red/58/

\section{Financiación}

Este estudio no ha recibido ningún tipo de subvención concreta de los organismos de financiación públicos, comerciales o sin fines de lucro existentes.

\section{Referencias}

Alcover, S. M., Pabago, G. M., Lombardo, R. A., Gareca, D. A. y Curone, G. N. (2015). Producción escrita argumentativa a partir de la lectura de textos académicos e informales por alumnos ingresantes a la universidad. Perspectivas en Psicología, 12(1), 1-7. Recuperado de https://dialnet.unirioja.es/servlet/articulo?codigo $=5115268$

Arrieta, B., Batista, J. T., Meza, R. D. y Meza., D. Y. (2006). La comprensión lectora y la redacción académica como centro del currículum. Acción pedagógica, 15, 9498. Recuperado de http://dialnet.unirioja.es/servlet/articulo?codigo=2968913

Álvarez, G. (2012). Entornos virtuales de aprendizaje y Didáctica de la Lengua: dos experiencias con integración de TIC para mejorar las habilidades de lectura y escritura de estudiantes preuniversitarios. Revista Q. Educación Comunicación Tecnología, 6(12), 1-23. Recuperado de https://dialnet.unirioja.es/servlet/articulo?codigo=3989798

Álvarez, G. y Bassa, L. (2013). TIC y aprendizaje colaborativo: el caso de un blog de aula para mejorar las habilidades de escritura de los estudiantes preuniversitarios. Revista de Universidad y Sociedad del Conocimiento (RUSC), 10(2), 5-19. Recuperado de http://www.redalyc.org/articulo.oa?id=78028681002

Álvarez, T., Mateo, T. y Serrano, M. P. (2015). Diseño de la plataforma RedacText 2.0 para ayudar a escribir textos académicos e investigar sobre enseñanza y aprendizaje de la escritura. Revista Complutense de Educación, 26(2), 425-445. Recuperado de http://revistas.ucm.es/index.php/RCED/article/view/43359

Álvarez, T., Mateo, T., Serrano, M. P. y González, M. A. (2015). Diseño de la plataforma RedacText 2.0 para ayudar a escribir textos académicos e investigar sobre enseñanza y aprendizaje de la escritura. Revista Complutense de Educación, 26(2), 425-445. Recuperado de http://revistas.ucm.es/index.php/RCED/article/view/43359

Escritura académica con Tecnologías de la Información y la Comunicación en Educación Superior. María Teresa Valverde González. 
Bennett, S. J., Maton, K. A. y Kervin, L. K. (2008). The 'digital natives' debate: a critical review of the evidence. British Journal of Educational Technology, 39(5), 775-786. Recuperado http://ro.uow.edu.au/cgi/viewcontent.cgi?article=2465\&context=edupapers

Bereiter, M. y Scardamalia, C. (1992). Dos modelos explicativos de los procesos de composición escrita. Infancia y aprendizaje, 58, 43-64. Recuperado de http://dialnet.unirioja.es/servlet/articulo?codigo $=48395$

Bolívar, A. y Montenegro, R. (2012). Producción de textos argumentativos escritos en estudiantes de décimo grado. Escenarios, 10(2). 92-103. En http://dialnet.unirioja.es/servlet/articulo?codigo $=4497300$

Bono, A. y Barrera, S. de la (1998). Los estudiantes universitarios como productores de textos. Una experiencia de docencia compartida. Revista Lectura y Vida, 19(4), 13-20.

Recuperado

de http://www.lecturayvida.fahce.unlp.edu.ar/numeros/a19n4/19_04_Bono.pdf

Cáceres-Lorenzo, M. T. y Santana-Alvarado, Y. (2014). La rúbrica de un taller de escritura para enseñar a sinohablantes en el contexto universitario europeo: estudio de caso. Porta Linguarum: Revista Internacional de Didáctica de las Lenguas Extranjeras, 21, 227-244. Recuperado de https://dialnet.unirioja.es/servlet/articulo?codigo $=4582318$

Camps, A. (2007). Comunicar en textos científicos y académicos [prólogo]. En M. Castelló (Coord.), Escribir y comunicarse en contextos científicos y académicos. Conocimientos y estrategias (pp. 9-12). Barcelona: Graó.

Carlino, P. (2003). Leer textos científicos y académicos en la educación superior: obstáculos y bienvenidas a una cultura nueva. Uni-pluri/versidad, 3(2), 1-9. Recuperado de https://aprendeenlinea.udea.edu.co/revistas/index.php/unip/article/viewFile/12289 $/ 11146$

Caro, M. T. y Valverde, M. T. (2014). Aprendizaje bimodal de las competencias comunicativa y digital en contextos formales de Educación Superior: la realización procesual de Trabajos Fin de Grado en Moodle. TEXTOS. Revista Internacional de Aprendizaje y Cibersociedad, 18(1), 43-53. Recuperado de http://ijqes.cgpublisher.com/product/pub.225/prod.22

Cassany, D. (2000). De lo analógico a lo digital. El futuro de la enseñanza de la composición. Lectura y Vida. Revista Latinoamericana de Lectura, 21(2), 1-11. En http://www.oei.es/fomentolectura/futuro_ensenanza_composicion_cassany.pdf

Cassany, D. y Morales, O. A. (2008). Leer y escribir en la universidad: Hacia la lectura y la escritura crítica de géneros científicos. Revista Memoralia. Recuperado de http://www.saber.ula.ve/handle/123456789/16457

Cayuela, A. M., Tauste, A., Seguí, M. M., Esteve, J. M. y Ronda, E. (2015). ¿Cómo medir el plagio entre alumnos universitarios? Revisión de instrumentos utilizados en artículos científicos. En M. T. Tortosa, J. D. Álvarez y N. Pellín (Coords.), XIII Libro de actas de las Jornadas de Redes de Investigación en Docencia Universitaria: Nuevas estrategias organizativas y metodológicas en la formación

Escritura académica con Tecnologías de la Información y la Comunicación en Educación Superior. María Teresa Valverde González. 
universitaria para responder a la necesidad de adaptación y cambio (pp. 210216). Recuperado de http://rua.ua.es/dspace/handle/10045/48708

Clerici, C., Monteverde, A. C. y Fernández, A. (2015). Lectura, escritura y rendimiento académico en ingresantes universitarios. Ciencia, Docencia y Tecnología, 26(50), 35-70.

Recuperado

de http://www.scielo.org.ar/scielo.php?script=sci_arttext\&pid=S185117162015000100002

Comisión Europea. (2004). Competencias clave para un aprendizaje a lo largo de la vida. Un marco de referencia europeo. Bruselas: Dirección General de Educación y Cultura.

Consejo de Europa. (2001). Marco común europeo de referencia para las lenguas: aprendizaje, enseñanza, evaluación. Estrasburgo: Unidad de Política Linguiística. Recuperado de http://cvc.cervantes.es/ensenanza/biblioteca_ele/marco/cvc_mer.pdf

Consejo de Europa. (2011). Cifras clave sobre el uso de las TIC para el aprendizaje y la innovación en los centros escolares de Europa 2011. Madrid: Catálogo de publicaciones del Ministerio de Educación de España.

Corcelles, M., Cano, M., Bañales, G. y Alicia, N. (2013). Enseñar a escribir textos científico-académicos mediante la revisión colaborativa: El trabajo final de grado en Psicología. Revista de Docencia Universitaria (REDU), 11(1), 79 - 104. Recuperado de https://polipapers.upv.es/index.php/REDU/article/view/5593/5584

Cortés, J. y García, S. (2013). Retos en el desarrollo de habilidades de escritura. En M. Vicente, T. González y M. Pacheco. Investigar la comunicación hoy. Revisión de políticas científicas y aportaciones metodológicas, Actas del Simposio Internacional sobre Política Científica en Comunicación (357-364). En http://dialnet.unirioja.es/servlet/articulo?codigo $=4228897$

Delgadova, E. y Gullerova, M. (2015). Comprensión lectora. Un estudio sobre la competencia lectora en el contexto universitario. Lenguaje y Textos, 41, pp. 4553. https://www.researchgate.net/publication/285594178_COMPRENSION_LECTO RA_Un_estudio_sobre_la_competencia_lectora_en_el_contexto_universitario

Drop, W. (1987). Planificación de textos con ayuda de modelos textuales. En E. Bernárdez (Comp.), Lingüística del texto (pp. 293-316). Madrid: Arco Libros.

Egaña, T. (2012). Uso de bibliografía y plagio académico entre los estudiantes universitarios. RUSC. Universities and Knowledge Society Journal, 9(2), 18-30. Recuperado de https://dialnet.unirioja.es/servlet/articulo?codigo=4602652

Eurydice (2012). El desarrollo de las competencias clave en el contexto escolar en Europa: desafíos y oportunidades para la política en la materia. Luxemburgo: Oficina de publicaciones de la Unión Europea.

Fairclough, N. (2003). El análisis crítico del discurso como método para la investigación en ciencias sociales. En R. Wodak y M. Meyer (Comp.), Métodos de análisis crítico del discurso (pp. 179-201). Barcelona: Gedisa Editorial.

Escritura académica con Tecnologías de la Información y la Comunicación en Educación Superior. María Teresa Valverde González. 
Fajardo, A. (2013). Actualización en el uso de la ortografía de la lengua española: desarrollo de objetos de aprendizaje mediante herramientas de las TIC. En M. J. Cuéllar y J. O’Dwyer, Innovación en las enseñanzas universitarias: experiencias presentadas en las III Jornadas de Innovación Educativa de la ULL (pp. 82-94). Santa Cruz de Tenerife: Universidad de la Laguna. Recuperado de http://www.ull.es/Private/folder/institucional/ull/calidad/innovacion/Libro_III\%20 Jornadas.pdf

Figueroa, B. y Aillon, M. (2015). Escritura académica de un ensayo mediado por el aprendizaje colaborativo virtual. Estudios pedagógicos, 41(1), 79-91. Recuperado de http://mingaonline.uach.cl/scielo.php?script=sci_arttext\&pid=S071807052015000100005\&lng=es\&nrm=iso\&tlng=es

Figueroa, B., Aillon, M., Fuentealba, A. (2014). La escritura académica con soporte de esquemas digitales en la formación docente. RUSC. Universities and Knowledge Society Journal, 11(1), 18-31. Recuperado de https://dialnet.unirioja.es/servlet/revista?codigo $=5805$

Flower, L. y Hayes, J. (1980). The cognition of discovery: Defining a rhetorical problem. College Composition and Communication, 31, 21-32. Recuperado de http://academic.brooklyn.cuny.edu/english/moser/eng\%207506/cognition\%20of\% 20discovery.pdf

Flower, L. S. y Hayes, J. R. (1981). A Cognitive Process Theory of Writing. College and Comunication, 32, 365-387. Recuperado de http://www.jstor.org/stable/356600?seq=1\#page_scan_tab_contents

Gallego-Ortega, J. L., García-Guzmán, A. y Rodríguez-Fuentes, A. (2013). Cómo planifican las tareas de escritura estudiantes universitarios españoles. RMIE. Revista Mexicana de Investigación Educativa, 18(57), 599-623. Recuperado de http://www.scielo.org.mx/pdf/rmie/v18n57/v18n57a13.pdf

Gallent, M. C. y Tello, I. (2017). Percepción del alumnado de traducción de la Universidad Internacional de Valencia (VIU) sobre el ciberplagio académico. RIDU, 11(2), 90-117. Recuperado de https://dialnet.unirioja.es/servlet/articulo?codigo $=6221904$

García, P. y Martí, A. (2017). TIC y escritura académica en el trabajo por proyectos. Textos de didáctica de la lengua y la literatura, 76, 38-42. Recuperado de http://www.grao.com/ca/producte/tic-y-escritura-academica-en-el-trabajo-porproyectos

Gómez, A. y Gómez, M. T. (2015). Escritura ortográfica y mensajes de texto en estudiantes universitarios. Perfiles Educativos, 37(150), 91-104. Recuperado de http://www.revistas.unam.mx/index.php/perfiles/article/view/53164

Gutiérrez, A. y Tyner, K. (2012). Educación para los medios, alfabetización mediática y competencia digital. Comunicar, 19(38), 31-39. Recuperado de http://www.revistacomunicar.com/index.php?contenido=detalles\&numero=38\&ar ticulo $=38-2012-05$

Gutiérrez, Y. (2009). Leer, escribir y hablar en la formación de estudiantes investigadores. Lectura y vida, 30(2), 58-70. Recuperado de https://dialnet.unirioja.es/servlet/articulo?codigo $=3076104$

Escritura académica con Tecnologías de la Información y la Comunicación en Educación Superior. María Teresa Valverde González. 
Hayes, J. (1996). A new framework for understanding cognition and affect in writing. En C. M. Levy y S. Ransdell (Eds.). The science of writing: theories, methods, individual differences, and applications (pp. 1-27). New Jersey: Lawrence Erlbaum Associates.

Izquierdo, B. Renés, P. y Gómez, O. (2013). La alfabetización mediática en la universidad a través de talleres multimodales de lectura y escritura académicas. Edmetic. Revista de Educación Mediática y TIC, 2(1), 76-94. Recuperado de http://www.edmetic.es/revistaedmetic/index.php/component/content/article?id=52

Jarpa, M. (2013). Una propuesta didáctica para el desarrollo de la escritura académica en estudiantes universitarios. Revista Iberoamericana de Evaluación Educativa, 6(1), 29-48. Recuperado de http://www.rinace.net/riee/numeros/vol6num1/art02.pdf

Llanos, L. y Villayandre, M. (2014). Nuevas tecnologías y escritura académica. En S. López y N. Pena, Humanidades Digitales: desafios, logros y perspectivas (pp. 263-275). Recuperado https://dialnet.unirioja.es/servlet/articulo?codigo=5181035

López-Cózar, C., Priede, T. y Benito S. (2013). Análisis de la expresión escrita en las Universidades de Madrid a través de la asignatura Trabajo de Fin de Grado en los estudios de ADE. Revista de Docencia Universitaria, 11(3). Recuperado de http://abacus.universidadeuropea.es/bitstream/handle/11268/2278/AnalisisDeLaE xpresionEscritaEnLasUniversidadesDeMa4558255.pdf? sequence $=1$ \&isAllowed $=\mathrm{y}$

Martín, M. E. (2011). Leer y escribir en la universidad: tarea pendiente. Álabe, 4, 1-21. Recuperado de http://revistaalabe.com/index/alabe/article/view/90

Melguizo, E. (2016). Los errores ortográficos en trabajos académicos de alumnos universitarios. En A. E. Díez, V. Brotons, D. Escandell y J. Rovira (Coords.), Aprendizajes plurilingües y literarios: Nuevos enfoques didácticos (pp. 521-532). Alicante: Universidad de Alicante.

Molina, B. (2013). Orientaciones metodológicas para trabajar las etapas de la producción textual en la preparación de los docentes en ejercicios Educación Primaria. Cuba: Universidad Máximo Gómez Báez de Ciego de Ávila.

Monzón, L. A. (2011). El blog y el desarrollo de habilidades de argumentación y trabajo colaborativo. Perfiles Educativos, 33(131), 80-93. Recuperado de http://www.scielo.org.mx/pdf/peredu/v33n131/v33n131a6.pdf

Morales, O. y Espinoza, N. (2005). El desarrollo de la escritura de estudiantes universitarios. Lectura y Vida: Revista Latinoamericana de Lectura, 26(1). 26-37. Recuperado de http://dialnet.unirioja.es/servlet/articulo?codigo=1176421

Muñoz, C. y Valenzuela, J. (2015). Características psicométricas de una rúbrica para evaluar expresión escrita a nivel universitario. Formación Universitaria, 8(6), 7584. http://www.scielo.cl/scielo.php?script=sci_arttext\&pid=S071850062015000600010 
Organización para la Cooperación y el Desarrollo Económicos. (2005a). La definición y selección de competencias clave [Resumen ejecutivo] (Trad. Agencia de los Estados Unidos para el Desarrollo Internacional). Washington, DC: USAID.

Organización para la Cooperación y el Desarrollo Económicos. (2005b). Habilidades y competencias del siglo XXI para los aprendices del nuevo milenio en los países de la $O C D E$ (Trad. Instituto de Tecnologías Educativas). Madrid: Ministerio de Educación.

Organización de las Naciones Unidas para la Educación, la Ciencia y la Cultura (2011). Alfabetización Mediática e Informacional: curriculum para profesores. París: Unesco

Padilla, C. (2012). Escritura y argumentación académica: trayectorias estudiantiles, factores docentes y contextuales. Magis, Revista Internacional de Investigación en Educación, 5(10), 31-57. Recuperado de http://www.redalyc.org/html/2810/281024896003/

Peirce, C. S. (2005). La ciencia de la semiótica. Buenos Aires: Ediciones Nueva Visión.

Prensky, M. (2001). Digital Natives, Digital Immigrants. On the Horizon, 9(5). En http://www.marcprensky.com/writing/Prensky\%20-

\%20Digital\%20Natives,\%20Digital\%20Immigrants\%20-\%20Part1.pdf

Saneleuterio, E. (2015). Revisión y recepción de la retroalimentación en Lengua Española para Maestros. Estudio comparativo. Huarte de San Juan. Filología y Didáctica de la Lengua, 15, 23-42. Recuperado de http://academicae.unavarra.es/handle/2454/20370

Serafini, M. T. (1994). Cómo se escribe. Barcelona: Paidós.

Saussure, F. (1945). Curso de Lingüística general. Buenos Aires: Losada.

Valverde, M. T. (2016). El desarrollo de la escritura académica con soporte digital para la formación inicial del profesorado (Tesis Doctoral). Universidad de Murcia, Murcia. Recuperado de https://dialnet.unirioja.es/servlet/tesis?codigo $=128237$

Wilson, C. (2012). Alfabetización mediática e informacional: proyecciones didácticas. Comunicar, 20(39), 15-24. Recuperado de http://www.revistacomunicar.com/index.php?contenido=detalles\&numero=39\&ar ticulo=39-2012-03

Wodak, R. y Meyer, M. (Comp.). (2003). Métodos de análisis crítico del discurso. Barcelona: Gedisa Editorial.

Escritura académica con Tecnologías de la Información y la Comunicación en Educación Superior. María Teresa Valverde González. 
